\title{
The neonicotinoid thiamethoxam impairs male fertility in solitary bees, Osmia cornuta ${ }^{\text {出 }}$
}

\author{
Verena Strobl ${ }^{\text {a, }}{ }^{*}$, Matthias Albrecht ${ }^{\mathrm{b}}$, Laura Villamar-Bouza ${ }^{\mathrm{a}, \mathrm{c}, 1}$, Simone Tosi ${ }^{\mathrm{d}}$, \\ Peter Neumann a, e, Lars Straub a, e \\ a Institute of Bee Health, Vetsuisse Faculty, University of Bern, Bern, Switzerland \\ b Agroscope, Agroecology and Environment, Zurich, Switzerland \\ ${ }^{c}$ European Food Safety Authority (EFSA), Pesticides Unit, Parma, Italy \\ d Department of Agricultural, Forest, and Food Sciences, University of Turin, Italy \\ e Agroscope, Swiss Bee Research Centre, Bern, Switzerland
}

\section{A R T I C L E I N F O}

\section{Article history:}

Received 5 February 2021

Received in revised form

22 March 2021

Accepted 5 April 2021

Available online 16 April 2021

\section{Keywords:}

Environmental pollutants

Solitary bee

Sperm traits

Thiamethoxam

\begin{abstract}
A B S T R A C T
The ongoing loss of global biodiversity is endangering ecosystem functioning and human food security. While environmental pollutants are well known to reduce fertility, the potential effects of common neonicotinoid insecticides on insect fertility remain poorly understood. Here, we show that field-realistic neonicotinoid exposure can drastically impact male insect fertility. In the laboratory, male and female solitary bees Osmia cornuta were exposed to four concentrations of the neonicotinoid thiamethoxam to measure survival, food consumption, and sperm traits. Despite males being exposed to higher dosages of thiamethoxam, females revealed an overall increased hazard rate for survival; suggesting sex-specific differences in toxicological sensitivity. All tested sublethal concentrations (i.e., 1.5, 4.5 and $10 \mathrm{ng} \mathrm{g}^{-1}$ ) reduced sperm quantity by $57 \%$ and viability by $42 \%$ on average, with the lowest tested concentration leading to a reduction in total living sperm by $90 \%$. As the tested sublethal concentrations match estimates of global neonicotinoid pollution, this reveals a plausible mechanism for population declines, thereby reflecting a realistic concern. An immediate reduction in environmental pollutants is required to decelerate the ongoing loss of biodiversity.
\end{abstract}

๑ 2021 Published by Elsevier Ltd. This is an open access article under the CC BY license (http:// creativecommons.org/licenses/by/4.0/).

\section{Introduction}

There is consensus that the ongoing loss of biodiversity is a defining feature of the Anthropocene (Dirzo et al., 2014; Ceballos et al., 2020; Wagner, 2020) with potentially drastic consequences for human food security and well-being (Díaz et al., 2019; Sala et al., 2000; Cardinale et al., 2012). Human population growth and increasing per capita consumption are considered to be the primary drivers of this decline, for instance through habitat loss (Dirzo et al., 2014; Ceballos et al., 2017), global warming (Soroye et al., 2020; Sales et al., 2018), or species invasions (van Kleunen et al., 2015). Environmental pollutants are another major factor and a notorious

\footnotetext{
This paper has been recommended for acceptance by Klaus Kümmerer.

* Corresponding author.

E-mail address: verena.strobl@vetsuisse.unibe.ch (V. Strobl).

1 Current affiliation of the author. The views of the author do not represent the views of her current employer.
}

side-effect of unsustainable human population growth and food production (Carvalho, 2006; Horejs, 2020; Silva et al., 2019). While understanding the specific mechanisms underlying how these factors affect entire populations remains challenging (SánchezBayo and Wyckhuys, 2019); undeniably negative effects on fertility will have fundamental consequences (Lumley et al., 2015). Indeed, over the past decades, common environmental pollutants, including plastics (e.g., Bisphenol A (BPA)) (Castellini et al., 2020) and agrochemicals (Dichlordiphenyltrichlorethan (DDT)) (Ratcliffe, 1967), have repeatedly been revealed to impair fertility and affect entire populations of a range of organisms. A male infertility crisis, as suggested for humans over the past decades (Ravitsky and Kimmins, 2019; Agarwal et al., 2020), has been reported in various other taxa due to environmental pollutants (Whorton et al., 1976; Bretveld et al., 2007; Bal et al., 2012; Humann-Guilleminot et al., 2019); offering a plausible key mechanistic pathway contributing to the ongoing decline of biodiversity.

Of particular concern are global insect declines as their role in sustaining ecosystem functioning and food security is 
indispensable (Wagner, 2020; Cardinale et al., 2012; Bélanger and Pilling, 2019). Neonicotinoid insecticides are a possible major driver of the current insect declines (Sánchez-Bayo and Wyckhuys, 2019; Woodcock et al., 2016) as they are the most widely used class of insecticides globally (Douglas et al., 2015). Inevitably, due to their non-specific mode of action, both lethal and sublethal effects on non-target organisms are well documented (Matsuda et al., 2020). These effects depend on the likelihood of exposure to such toxicants (e.g., via food consumption (Desneux et al., 2007; SánchezBayo, 2014)) and may vary within a single species (e.g., between sexes (Friedli et al., 2020; Brandt et al., 2020)). If neonicotinoids impact male insect fertility analogous to other environmental pollutants (discussed above) the resulting effects on insect populations and downstream effects on ecosystem stabilty and food security would be a major concern. However, the effects of neonicotinoids on male insect fertility remain largely unexplored and are unknown for key functional insect groups such as solitary bees, thereby constituting a pivotal knowledge gap.

Generalist solitary bees play important ecological and economic roles (Westrich, 1989; Torchio and Asensio, 1987). The common genus Osmia constitutes an ideal model to assess potential insecticide-induced male infertility. Since females of this genus only mate once, males can therefore only increase their fitness by inseminating several females (Seidelmann, 2014a). Subsequently, sperm quantity is a critical trait affecting population dynamics. Likewise, sperm viability is essential to ensure egg fertilization (Birkhead et al., 2009). Inviable sperm may result in more males emerging from unfertilized eggs, due to complementary sex determination in Hymenoptera (Beye et al., 2003). Indeed, stronger shifts in male-biased sex-ratios have been reported postneonicotinoid insecticide exposure (Sandrock et al., 2014; Stuligross and Williams, 2020), which may result from male infertility. Especially in species with single-mated females (Thornhill and Alcock, 1983) and/or males with per se poor sperm viability (Strobl et al., 2019), male infertility could have drastic consequences, thereby providing a plausible explanation for the observed insect declines (Woodcock et al., 2016; Rundlöf et al., 2015).

Here, we used standard laboratory methods (Strobl et al., 2019; Strobl et al., 2020) to investigate infertility in male bees, Osmia cornuta, exposed to field-realistic concentrations of the neonicotinoid insecticide thiamethoxam. For that purpose, we measured the effects of thiamethoxam on survival, food consumption, and sperm traits. We hypothesize that field-realistic sublethal dosages would negatively affect male fertility.

\section{Material and methods}

Experimental set-up: The study was performed at the Institute of Bee Health (Bern, Switzerland), between March and August 2019. In March, 200 male and 200 female $O$. cornuta previously sexed cocoons were purchased from WAB - Mauerbienenzucht (mauerbienen.com), and stored at $2{ }^{\circ} \mathrm{C}$ and $60 \%$ relative humidity (RH) until early April. Then, the sexed cocoons were transferred to room temperature (RT, $\sim 24{ }^{\circ} \mathrm{C}$ ), and placed in separate cages (BugDorm - Insect rearing cage [47.5 x $47.5 \times 47.5 \mathrm{~cm}$ ], Megaview Science Co. Ltd., Taiwan) so we could guarantee that mating was avoided, which would have influenced the sperm assessments later. The cocoons remained in their respective cages until all individuals had emerged. Further, to establish known age cohorts, emergence time and emergence mass (hereafter, start mass) were recorded daily over $96 \mathrm{~h}$ (time required for male sexual maturity (Strobl et al., 2019)) upon the first observed cocoon eclosion for each sex resulting in a total of 308 adults $\left(N_{\text {females }}=165\right.$ and
$N_{\text {males }}=143$ ). All remaining individuals were omitted from the experiment. Furthermore, males and females that emerged in the wrong cages due to incorrect cocoon sexing were immediately removed and excluded from the experiment $\left(N_{\text {females }}=0\right.$ and $N_{\text {males }}=2$ ). Upon eclosion, all individuals were visually assessed for abnormalities (e.g., ectoparasite infestations, clinical disease symptoms, or morphological deformations (Browne, 1922; Bosch, 1992; Seidelmann, 2006)), but none displayed any. Females and males from each age cohort (i.e., day 1-4) were then placed in individual cages $\left[80 \mathrm{~cm}^{3}\right]$, and randomly assigned to one of five treatment groups: Control $\left(N_{\text {females }}=35 ; N_{\text {males }}=30\right)$ or one of four thiamethoxam concentrations (1.5 $\mathrm{ng} \mathrm{g}^{-1}\left(N_{\text {females }}=32\right.$; $\left.N_{\text {males }}=29\right), 4.5 \mathrm{ng} \mathrm{g}^{-1}\left(N_{\text {females }}=33 ; N_{\text {males }}=30\right), 10 \mathrm{ng} \mathrm{g}^{-1}$ $\left.\left(N_{\text {females }}=35 ; N_{\text {males }}=29\right), 100 \mathrm{ng} \mathrm{g}^{-1}\left(N_{\text {females }}=30 ; N_{\text {males }}=25\right)\right)$. Cages were maintained at RT with indirect natural light (Strobl et al., 2019). Apart from the $100 \mathrm{ng} \mathrm{g}^{-1}$ concentration, which acted as a positive control for mortality, the tested concentrations reflect a field-realistic exposure scenario (Tosi et al., 2017; Tosi and Nieh, 2017), as residue analyses have revealed similar concentrations in nectar as well as honeydew (Zioga et al., 2020; Calvo-Agudo et al., 2019; Martínez-Ferrer et al., 2019). Each individual was given $50 \%[w / w]$ sucrose-solution (white granulated sugar (Landi $A G \AA$, Dotzingen, Switzerland)) via a five [ml] syringe (Codan Medical AG, Switzerland) and pollen paste (60\% fresh honey bee-collected corbicular pollen and $40 \%$ sugar powder) via a modified Eppendorf $₫$ tube ad libitum, thereby allowing for tissue and organ development (Wasielewski et al., 2011; Cane, 2016). To test for potential residues in the provided pollen, the French National Center for Scientifc Research analyzed a subsample of the corbicular pollen for a selected range of common agricultural chemicals, including thiamethoxam, using ultra-high-performance liquid chromatographytandem mass spectrometry (UHPLC-MS/MS). The residue analysis revealed that thiamethoxam as well as its primary metabolite (clothianidin) were not present (see SI Table 3); however, two chemicals were detected above the limit of quantification (acetamiprid at $0.6 \mathrm{ng} \mathrm{g}^{-1}$ and thiacloprid at $0.13 \mathrm{ng} \mathrm{g}^{-1}$ ). These low residues are likely negligible as previous studies using acetamiprid (482.93 $\mathrm{ng} \mathrm{g}^{-1}$ ) (Azpiazu et al., 2019) and thiacloprid (500 $\mathrm{ng} \mathrm{g}^{-1}$ ) (Brandt et al., 2020) at concentrations several oders of magnitude higher only observed significant sublethal effects in Osmia bicornis. Furthermore, all treatments including the controls received the same pollen.

Insecticide solution preparation: Thiamethoxam (99\% purity, Sigma-Aldrich, UK) was dissolved in $40 \mathrm{ml}$ distilled water to produce a primary stock solution $\left(1 \mathrm{mg} \mathrm{ml}^{-1}\right)$. An aliquot of the primary stock solution was then used to produce a second solution with a $10 \mu \mathrm{g} / \mathrm{L}\left(10 \mathrm{ng} \mathrm{g}^{-1}\right)$ thiamethoxam concentration. Varying volumes of the second solution were added to a $50 \%[\mathrm{w} / \mathrm{w}]$ sucrosesolution to produce the four desired concentrations. Bees were chronically exposed to their respective treatments for four days at which point the males were considered sexually mature and typically mate (Strobl et al., 2019; Seidelmann, 2015). As under the given conditions (i.e., indirect light exposure and constant RT) neonicotinoids are considered to be stable and show high persistence and low degradation times (Schläppi et al., 2020), the feeders were not exchanged.

Assessments of consumption, exposure, and survival: Within our study, the quantification of pollen consumption was not feasible, because the bees tended to remove and spread pollen through the entire cage as observed in a previous study (Brandt et al., 2020). Therefore, all consumption data refer to sucrose-solution only. Total consumption was recorded by measuring the mass of the syringe at the beginning and either at the point of death or after four days. En passant this enabled to calculate the exact thiamethoxam-exposure 
rates for each bee. In addition, to enable precise measurements, evaporation was measured by using five empty cages containing a syringe with sucrose-solution. The results revealed that evaporation across the four-day exposure period was below $1.7 \%$ and thus considered negligible. To correct for the sexual body-size dimorphism in Osmia spp. (Raw, 1972) and possible effects on consumption and exposure, we calculated the relative daily consumption by dividing the total consumption by the bees' start mass and days alive only for individuals that survived the $96 \mathrm{~h}$ exposure period. Regardless of the bees' age, relative total exposure was calculated by dividing the total exposure by the individual's start mass. Whereas, relative daily exposure was determined by dividing the total exposure by individual body mass and days alive. In contrast, for all other tested endpoint variables (i.e., mortality and sperm traits), the total exposure was used for the analyses. Total exposure was calculated by multiplying the mass of consumed sucrose-solution (i.e., g) by the concentration of the respective pesticide (i.e., $\mathrm{ng} \mathrm{g}^{-1}$ ). Mortality was recorded every $12 \mathrm{~h}$. The survival analysis for both sexes was terminated after four days and all surviving males were used for assessing sperm traits.

Sperm assessment: Following Seidelmann (2015), the entire male genitalia was dissected from $\mathrm{CO}_{2}$ anaesthetized individuals, including the granular gland, accessory gland, vesical seminalis, and testis (Fig. 1A), and placed in a $1.5 \mathrm{ml}$ Eppendorf tube containing $200 \mu \mathrm{l} \mathrm{Kiev}{ }^{+}$buffer. Following Straub et al. (2016) and Strobl et al. (2019), sperm quantity (i.e., total number of sperm produced), sperm viability (i.e., proportion of sperm alive), and total living sperm (i.e., product of multiplying the determined sperm quantity by sperm viability) were assessed. A detailed description of the sperm assessment can be found in the supplementary information.

Statistical analyses: The Shapiro-Wilk's and the Levene's test were used to test data and model residues for normal distribution and homogeneity of variances, and to choose statistical tests accordingly. Multilevel generalized logistic (GLMMs) or linear (regression) models (LMMs) with random intercepts were fitted using STATA16 (StataCorp, 2019), wherein individual bees were considered independent units, treatment (insecticide vs control), and sex were included as the explanatory (fixed) terms and whenever applicable fixed co-variates (e.g., emergence time, start mass, relative total exposure) were incorporated (Leckie, 2010). For each multiple regression model, a stepwise backward elimination approach was applied to determine the model of best fit (Wiegand, 2010). Best fit models were chosen by comparing every multi-level model with its single-level model counterpart using both a likelihood ratio (LR) test as well as the Akaike information criterion (AIC) and the Bayesian information criterion (BIC), using the functions lrtest and estat ic, respectively (Sribney and StataCorp, 2005). Whenever appropriate, the means \pm the standard error (SE) (adjusted for distribution) are given in the text and are further provided in Supplementary Information (SI) Table 1. In addition, summary statistics for all measured variables are provided in SI Table 2 together with the results for the effects of all fixed (i.e., sex or treatments) and co-variates (i.e., emergence time and start mass). All statistical figures were created using NCSS 20 (NCSS, 2020).

Relative daily consumption $\left[\mathrm{g} \mathrm{g}^{-1}\right]$ was non-Normally

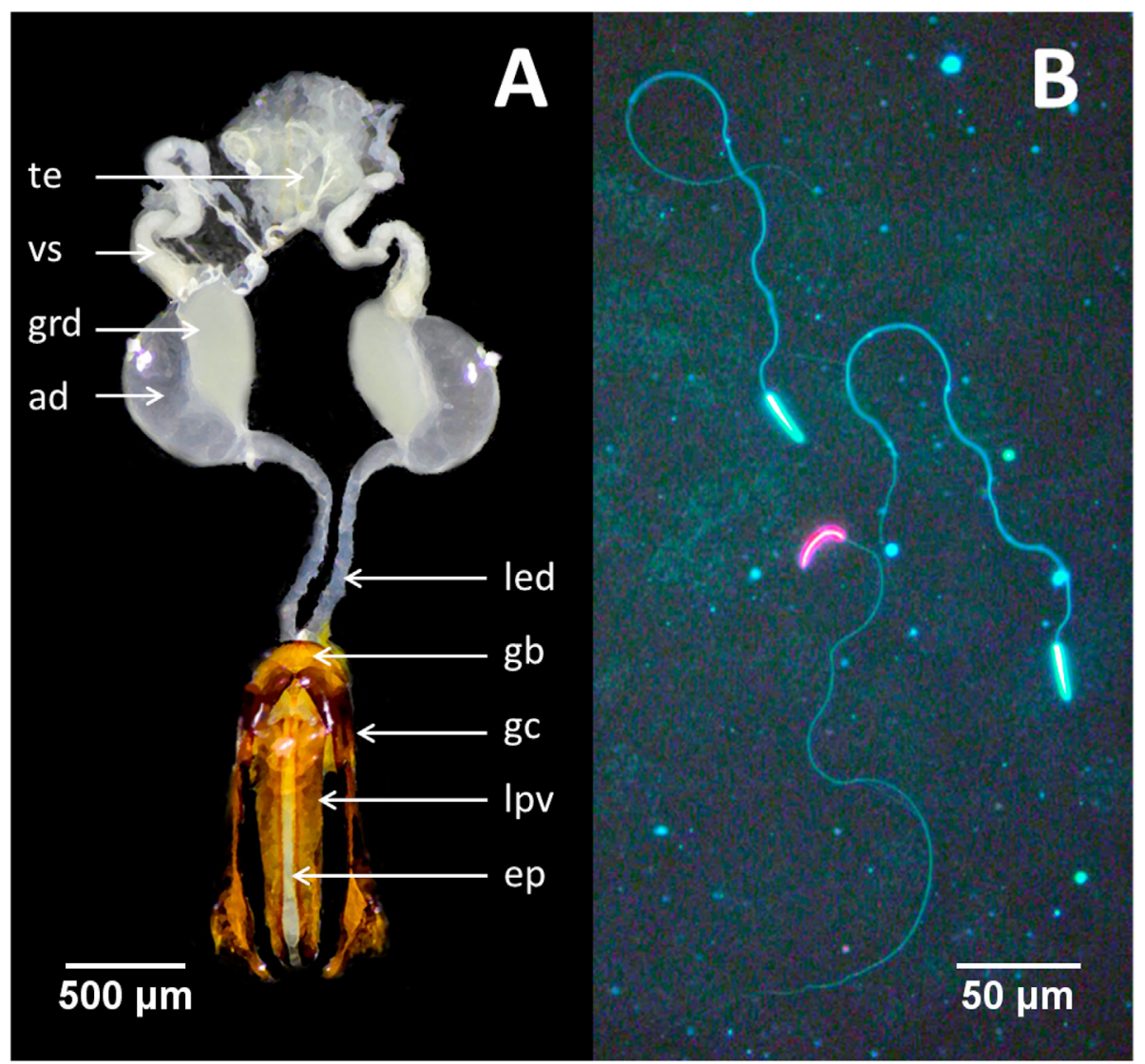

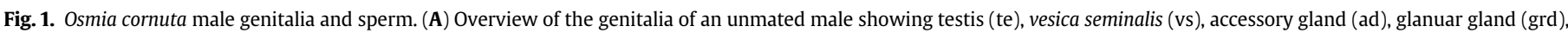

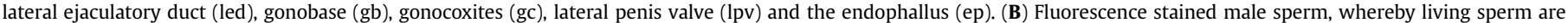

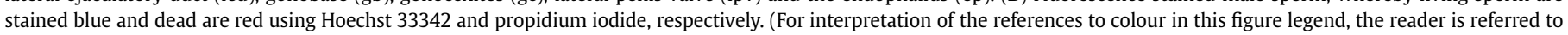
the Web version of this article.) 
distributed (Shapiro-Wilk's test, $\mathrm{p}<0.05$ ) and was modelled with a GLMM following error Gamma distribution, including start mass [g] as a random factor. Relative daily exposure $\left[\mathrm{g} \mathrm{g}^{-1}\right]$ was also nonNormally distributed (Shapiro-Wilk's, $\mathrm{p}<0.001$ ), due to a zero inflation effect caused by the large number of zeros for the exposure values of the control treatment. Therefore, using the function zip, we applied a zero-inflated Poisson model using treatment and relative daily exposure as fixed effects to analyzed the data with excess zero counts (Xie et al., 2012). This model adequately captures excess zeros by calculating incidence rate ratios separately for the zero inflation in both treatment and exposure effects. The zero inflation was significant for both factors (both $p$ 's $<0.001$ ) and thus the model rendered incidence rate ratios for the treatment and relative daily exposure terms without the excess zeros. Relative total exposure [ng $\mathrm{g}^{-1}$ ] was modelled with a GLMM using the function meglm and applying a Gamma error distribution. As sperm viability is a score ranging from 0 to $100 \%$ and not count data, an ordered logistic model was fitted using the function meologit. Survival time was set using the function stset and individuals surviving the exposure period were censored using the if option. The survival data were then analyzed using the mestreg function for multilevel survival models (Cleves, 2002). Survival was calculated by using cumulative survival rates [\%] after four days for each treatment. Furthermore, to assess the effect of thiamethoxam exposure on survival amongst sexes, the proportional hazards (PH) model was applied (Cleves et al., 2016). The model enables the calculation of a regression coefficients, in our case the hazard rate of a specific group (i.e., males) compared to another treatment group (i.e., females). Survival curves (Kaplan Meier plots) and smooth estimated hazard rate plots with $95 \%$ confidence intervals $(\mathrm{CI})$ were used to visually display the survival data. Post-hoc comparisons amongst treatment groups for all variables were conducted using the Bonferroni multiple pairwise comparisons test $(b m c t)$, using the function mcompare() and option bonferroni whenever necessary (Mitchell, 2012). In addition, linear mixed models (LMMs) were applied to determine the relationship amongst endogenous factors (i.e., emergence time [h] and start mass [mg]) and outcome variables (i.e., longevity, sperm quantity, sperm viability, and total living sperm) using the function xtmixed.

\section{Results}

Consumption and exposure: Irrespective of sex and treatment, heavier bees were consuming more sucrose-solution resulting in a significant positive correlation between total consumption and start mass $(z=3.31, p<0.001)$. In contrast, emergence time revealed no significant effect on total consumption $(z=-0.87$, $p=0.385$ ). Likewise, insecticide exposure revealed no significant effect on total consumption for either sex (Bonferroni multiple comparison test (bmct); all p's > 0.17; Table 1 ). When accounting for body mass, a sex-specific difference was observed for daily consumption across all treatments $\left(\chi^{2}=83.77, z=8.21, p<0.001\right)$, wherein males $(1.03 \pm 0.05)$ revealed a 2.1 fold increase in consumption compared to females $\left(0.49 \pm 0.03\right.$ ) (mean \pm SE $\left[\mathrm{g} \mathrm{g}^{-1}\right.$ day $\left.^{-1}\right]$ ). Subsequently, males were exposed to significantly higher dosages of thiamethoxam compared to females $(z=13.35$, $p<0.001$; Table 1); with relative total exposure in the $1.5,4.5,10$, and $100 \mathrm{ng} \mathrm{g}^{-1}$ treatment being $1.87,1.80,1.76$, and 1.60 fold higher in males, respectively (Fig. 2a). Lastly, the relative daily exposure exponentially increased with increasing concentrations for both sexes, wherein a significant sex-specific difference was observed for each treatment group (bmct; all p's $<0.001$; Fig. 2a).

Survival: For both sexes, emergence time had no significant effect on survival $(z=-1.03, p=0.29)$; whereas start mass revealed a positive effect $(z=2.17, p<0.03)$. Further, a negative correlation

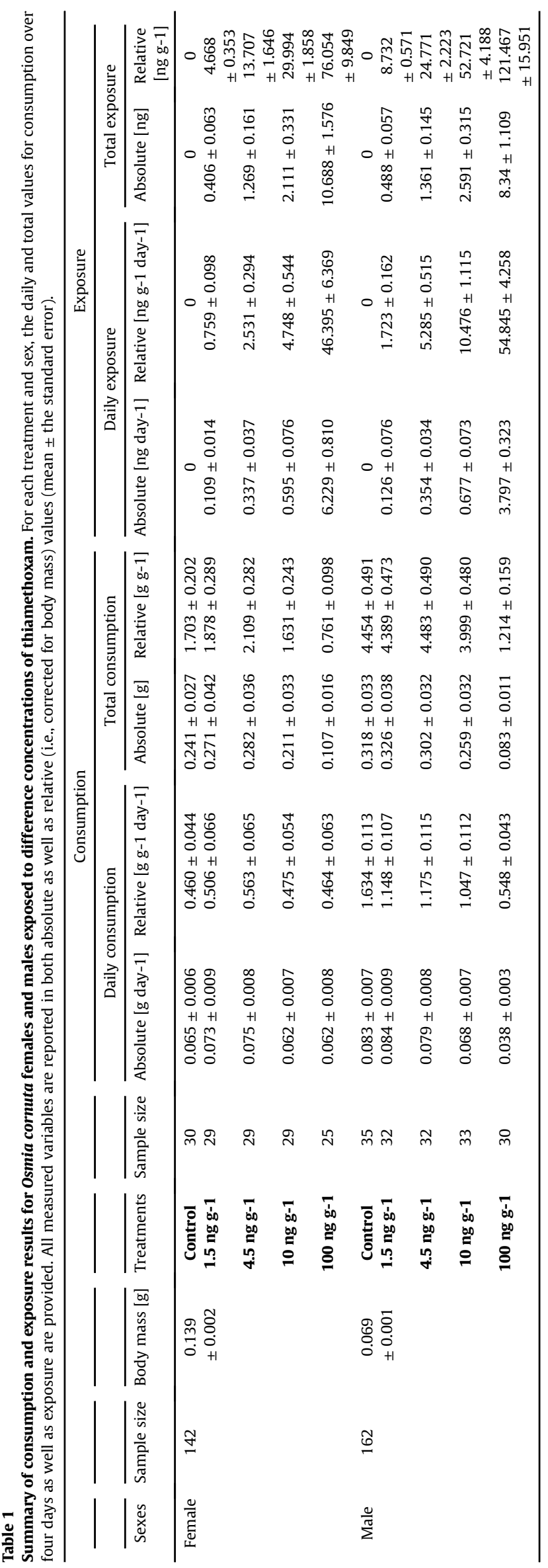



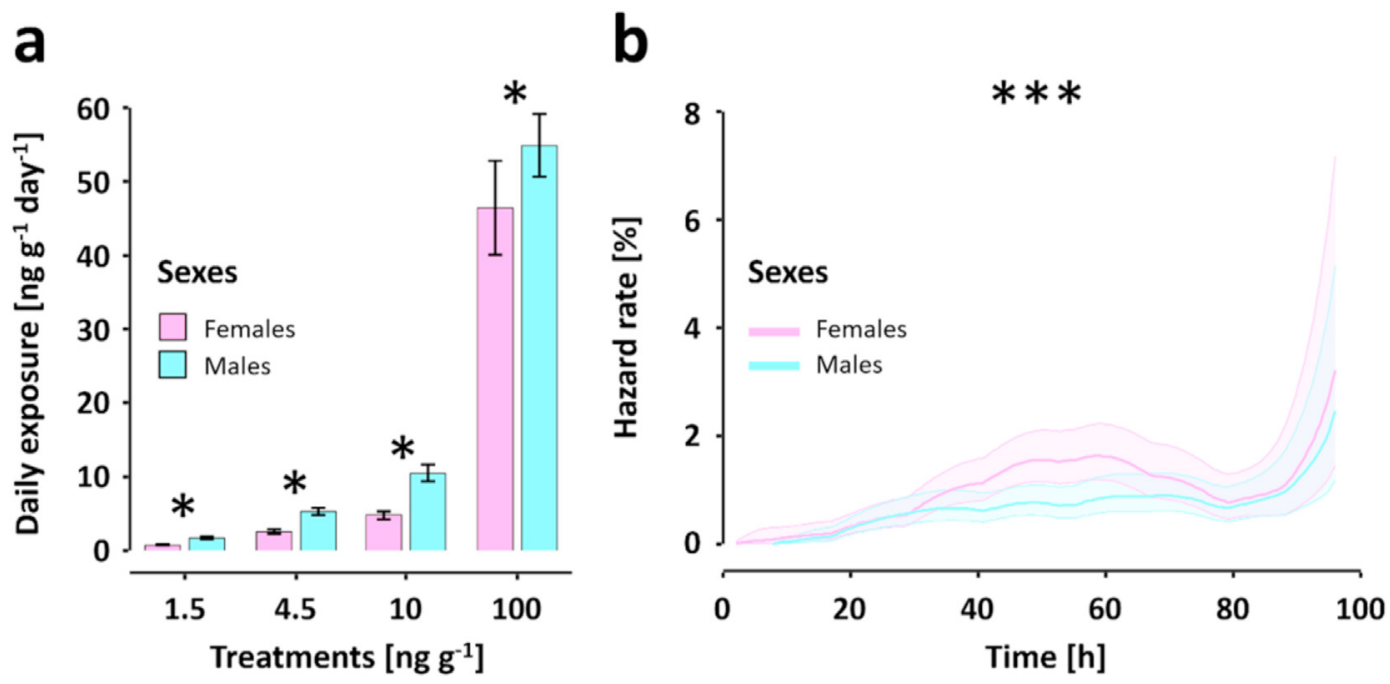

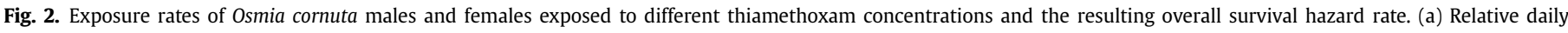

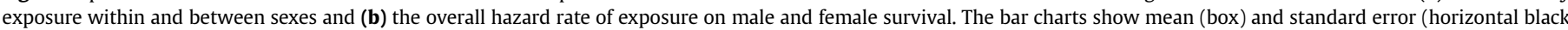

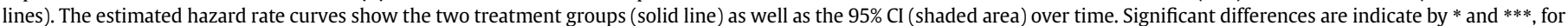
$p<0.05$ and $p<0.001$, respectively.

was observed between relative total exposure and survival for both males and females $\left(\chi^{2}<21.73, z=4.13, p<0.001\right)$. However, the negative effect of increasing total exposure on survival was stronger in females $(z=-3.14, p=0.002)$ and, irrespective of the concentration, resulted in an increased hazard rate of $42 \%$ in comparison to the males (Fig. 2b). Control mortality rates did not significantly differ between sexes (multiple effects survival time regression (mestreg); $\chi^{2}=0.07, p=0.96$ ); where female and male survival rates after four days were $73.3 \pm 58-89 \%$ and $74.3 \pm 60-89 \%$, respectively (median $\pm 95 \% \mathrm{CI}$ ). Female control survival did not significantly differ from the 1.5 or $4.5 \mathrm{ng} \mathrm{g}^{-1}$ treatment groups (bmct; $p>1.0$; Fig. 3a); yet a significant difference was observed when compared to the 10 and $100 \mathrm{ng} \mathrm{g}^{-1}$ treatment groups (bmct; $p<0.04$; Fig. 3a). No significant difference was revealed amongst female 1.5, 4.5 and $10 \mathrm{ng} \mathrm{g}^{-1}$ (bmct; $p>0.18$; Fig. 3a). The $100 \mathrm{ng} \mathrm{g}^{-1}$ revealed the lowest survival that differed from all other treatment groups (bmct; $p<0.001$; Fig. 3a). In contrast, male control survival only significantly differed from the $100 \mathrm{ng} \mathrm{g}^{-1}$ (bmct; $p<0.001$; Fig. 3b) which showed the lowest survival across all treatment groups (bmct; $p<0.001$; Fig. 3b). From the female and male
$100 \mathrm{ng} \mathrm{g}^{-1}$ treatment groups, only one male individual survived the four day exposure period, therefore these treatment groups were excluded from the following analyses.

Sperm traits: Start mass had a positive effect on sperm quantity $(z=2.09, \mathrm{p}<0.04)$, yet no significant effect on sperm viability or total living sperm (both $z$ 's $<-0.29$, $p$ 's $>0.32$ ). The contrary was the case for emergence time, which revealed a negative effect on both sperm viability and total living sperm (both $z$ 's $>3.82$, $p$ 's $<0.001$ ), whereas no effect on sperm quantity was revealed $(z=1.34 \mathrm{p}>0.18)$. All sperm traits were significantly negatively affected by insecticide exposure (all $z$ 's $<-2.45$, all $p$ 's $<0.02$ ). Control sperm quantity was higher when compared to all other treatment groups (bmct, $p<0.02$; Fig. $4 \mathrm{a}$ ), yet no significant difference was observed amongst the thiamethoxam treatment groups (bmct; all p's > 0.44; Fig. 4a). Sperm quantity across all thiamethoxam exposed individuals $(195 \pm 16)$ was roughly $57 \%$ lower compared to controls $(454 \pm 18)$ (mean \pm SE [thousand]). Similarly, control sperm viability $(53.6 \pm 3.8)$ differed from the $1.5 \mathrm{ng} \mathrm{g}^{-1}(21.4 \pm 3.8), 4.5 \mathrm{ng} \mathrm{g}^{-1}(39.2 \pm 3.1)$, and $10 \mathrm{ng} \mathrm{g}^{-1}$ $(32.2 \pm 4.0)$ treatment groups (bmct, all p's < 0.001; Fig. 4b);
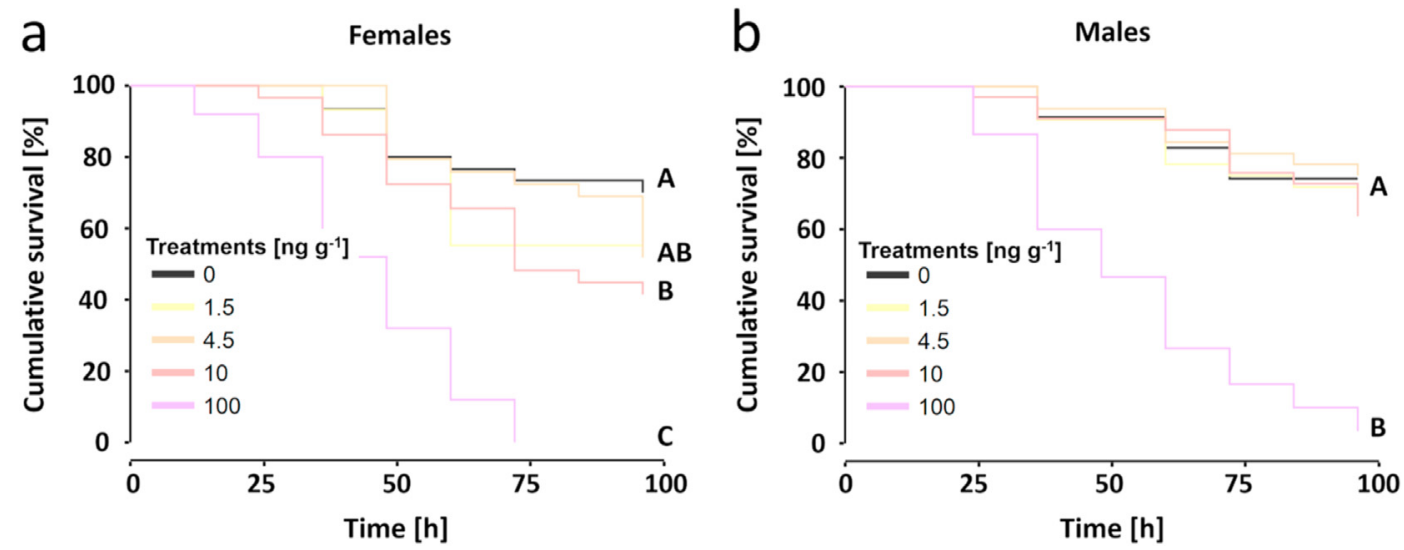

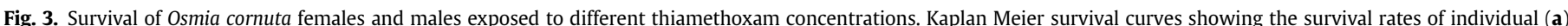

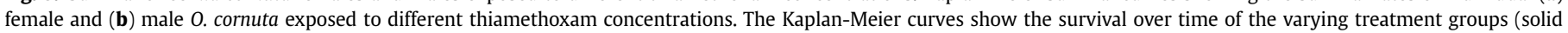
lines). Capital letters indicate pairwise significant differences amongst concentrations (mestreg, $p<0.05$ ). 


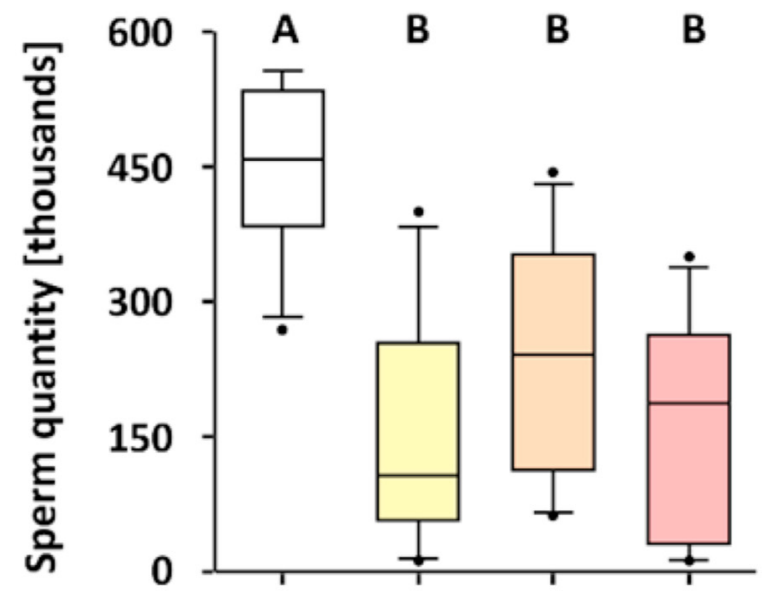

b

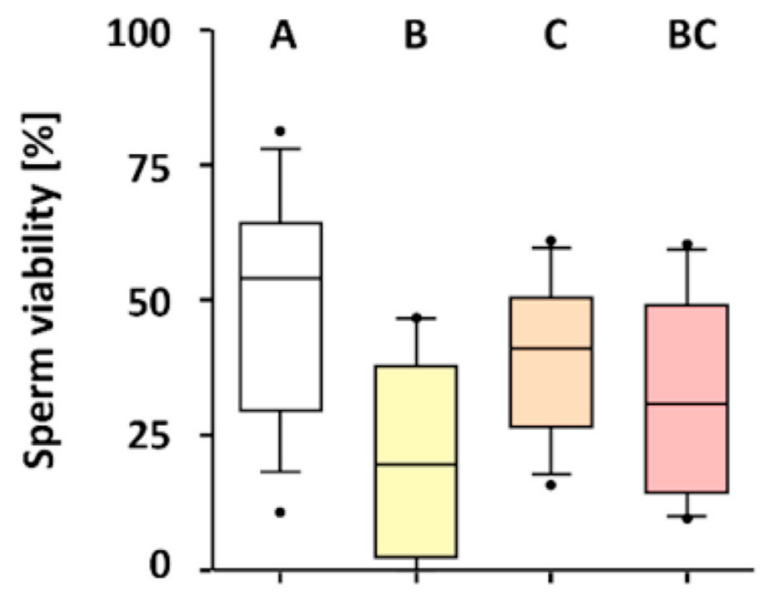

C

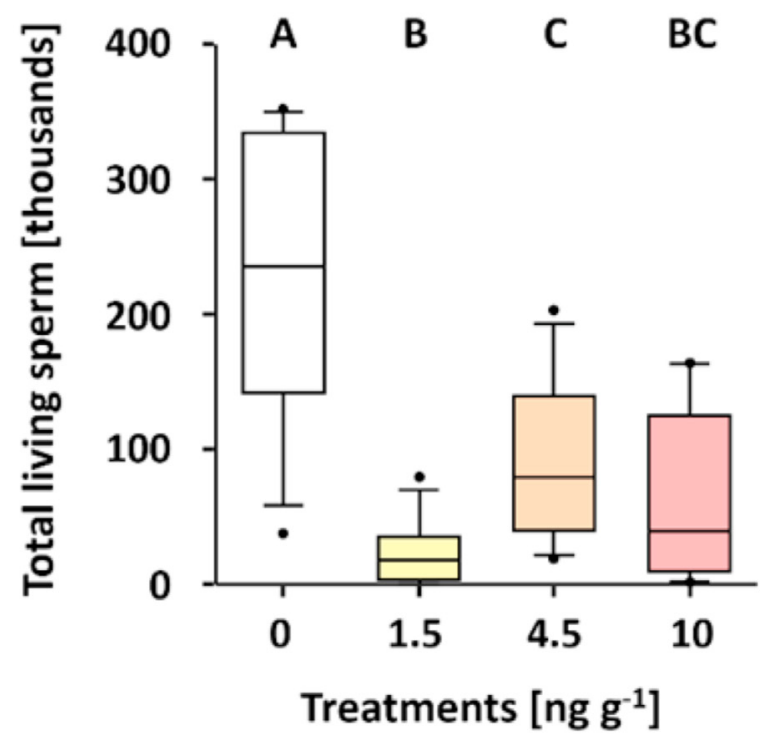

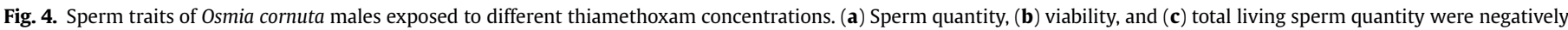

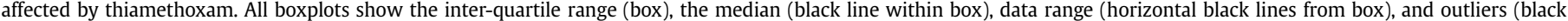
dots). Pairwise significant differences between each pesticide and control groups are indicated by different capital letters $(p<0.05)$. 
resulting in a reduction of $60 \%, 27 \%$ and $40 \%$, respectively. Across all treatment groups, this reflects a reduction in sperm viability of $42 \%$. Moreover, sperm viability differed between the 1.5 and $4.5 \mathrm{ng} \mathrm{g}^{-1}$ treatment group (bmct, $p=0.013$; Fig. $4 \mathrm{~b}$ ), but neither of them differed from the $10 \mathrm{ng} \mathrm{g}^{-1}$ treatment group ( $b m c t$, both $p$ 's $>0.026$; Fig. 4b). Lastly, control total living sperm differed from all thiamethoxam treatment groups (bmct, $p<0.001$; Fig. 4c); revealing the highest total living sperm quantity $(247 \pm 21$; mean \pm SE [thousands]). The $1.5 \mathrm{ng} \mathrm{g}^{-1}(24 \pm 5)$ revealed the lowest total living sperm quantity which differed from the $4.5 \mathrm{ng} \mathrm{g}^{-1}(96 \pm 13)$ treatment group (bmct, $p=0.004$; Fig. 4c), but not from the $10 \mathrm{ng} \mathrm{g}^{-1}(64 \pm 14)$ treatment group (bmct, $p>0.44$; Fig. 4c) (mean \pm SE [thousands]). No significant difference was observed between the 4.5 and $10 \mathrm{ng} \mathrm{g}^{-1}$ treatment groups (bmct, $p>0.71$; Fig. 4c). In comparison to the controls, this lead to a reduction of total living sperm for the lowest to highest insecticide treatment group of $90 \%, 61 \%$, and $74 \%$, respectively; resulting in a reduction across all treatments of $75 \%$.

\section{Discussion}

The data clearly show that the lowest exposure to a common neonicotinoid insecticide $(0.49 \mathrm{ng})$ impaired male fertility of solitary bees, $O$. cornuta, by reducing total living sperm quantity by $90 \%$. Our data suggest that male insect fertility can be adversely impacted by exposure to environmentally-relevant concentrations of thiamethoxam (Mitchell et al., 2017), an effect that could have far reaching consequences on insect populations. Taken together with similar reports from other species, including humans (Agarwal et al., 2020), it therefore appears as if male infertility due to environmental pollutants (e.g., DDT (Njiwa et al., 2004; Rhouma et al., 2001), plastic (Castellini et al., 2020) and neonicotinoids (this study)) may be a driving force behind the ongoing declines in biodiversity.

Overall, the data suggest that short-term chronic thiamethoxam exposure below $10 \mathrm{ng} \mathrm{g}^{-1}$ had no significant effect on survival. Interestingly, $O$. cornuta appears to have a higher tolerance towards thiamethoxam compared to honey bee, A. mellifera, workers (Thompson and Pamminger, 2019), possibly due to varying detoxification abilities (Arena and Sgolastra, 2014; Beadle et al., 2019) and workers being replaceable units (Straub et al., 2015). As no significant reduction in consumption was observed for either sex exposed to thiamethoxam concentrations up to $10 \mathrm{ng} \mathrm{g}^{-1}$, detoxification deficiencies due to bees avoiding contaminated food and thus starving can likely be excluded (Turturro et al., 2000). In line with previous findings, our results showed that males consumed significantly more than their female counterparts, despite being smaller (Brandt et al., 2020). Irrespective of the underlying cause, exposure scenarios between sexes can therefore vary, explaining the observed 1.9-fold increase in exposure in males compared to females. Despite males being exposed to higher dosages of thiamethoxam, females revealed an overall increased hazard rate for survival. This became further apparent in the $10 \mathrm{ng} \mathrm{g}^{-1}$ treatment group, where female survival was significantly lower compared to controls, which was not the case for males. Sex-specific differences in toxicological sensitivity have been documented for bees (Friedli et al., 2020); possibly due to differences in body size and/or detoxification abilities (Brandt et al., 2020; Muth et al., 2020; Mobley and Gegear, 2018).

Across all neonicotinoid treatments, an average reduction in sperm quantity by $57 \%$ was observed in comparison to the controls. Past studies on honey bee, A. mellifera, drones revealed no such reduction after neonicotinoid exposure during larval development or adulthood (Straub et al., 2016; Ciereszko et al., 2017). As spermatogenesis and spermiogenesis are completed upon emergence in all bees (Breeze et al., 2020), our findings suggest that thiamethoxam may hinder the migration of sperm from the testis to the seminal vesicles in solitary bees (Snodgrass, 1962). In contrast to eusocial honey bees (Koeniger, 1986; Duchateau and Mariën, 1995), solitary bees are considered to be capable of mating directly post eclosion (Strobl et al., 2019; Seidelmann, 2015). Therefore, speciesspecific differences in reproductive physiology, behaviour, and lifehistory may alter the susceptibility towards a chemical (Baron et al., 2017). This further underlines that eusocial honey bees are not suitable surrogates for solitary bees for ecotoxicological risk assessment (Wood et al., 2020). Considering that male bees of the genus Osmia as well as of other solitary bee genera are polygynous (Smith, 1984), such a reduced sperm quantity constitutes a clear fitness constraint as their natural insemination capacity is substantially reduced (Seidelmann, 2015). Assuming the same efficacy of the sperm transfer from the female oviducts to the spermatheca as in honey bees ( 10\% (Bresslau, 1905; Woyke and Ruttner, 1958)), a male must release $\sim 40^{\prime} 000$ sperm to ensure the filling of the female spermatheca (Fliszkiewicz et al., 2013). Consequently, the observed control male sperm quantity would be sufficient to inseminate 11 females, which is in line with previous observations (Seidelmann, 2015). In sharp contrast, the observed drastic reduction of sperm quantity for all neonicotinoid-exposed males would suggest that only up to four females could sufficiently be inseminated; reflecting a reduction of male fitness by $64 \%$.

Irrespective of sperm quantity, it is essential that sperm is alive to enable fertilization of eggs (Birkhead et al., 2009). Across all tested concentrations a reduction of sperm viability by $\sim 42 \%$ was revealed. This may be due to increased oxidative stress (Collins et al., 2004), impaired function of mitochondria in sperm (Ciereszko et al., 2017), or reduced seminal fluid protein abundance (Baer et al., 2009). Even in the absence of environmental stressors, O. cornuta sperm viability is relatively low compared to other bees (i.e., 65\% (Strobl et al., 2019) and may reflect relaxed selection pressures on males of monandrous insects to maintain sperm (Hunter and Birkhead, 2002). This could explain the increased vulnerability of sperm viability in 0 . cornuta towards neonicotinoid pollution compared to eusocial honey bees by one order of magnitude (Straub et al., 2016). The far more severe reduction in viability of $O$. cornuta sperm was already apparent in the lowest tested concentration (i.e., 1.5 in this study vs. $4.9 \mathrm{ng} \mathrm{g}^{-1}$ for A. mellifera (Straub et al., 2016)). Since the survival data suggest that o. cornuta may have a higher overall tolerance towards thiamethoxam (see above), our findings appear to reflect a trade-off scenario between survival and fertility, which is known from other systems (Schwenke et al., 2016; Henry et al., 2015). Finally, the reduced sperm quantity and viability observed across all neonicotinoid concentrations led to a drastic reduction in total living sperm quantity by $75 \%$. Of particular concern is that the lowest tested concentration (i.e., $1.5 \mathrm{ng} \mathrm{g}^{-1}$ ) showed the most severe effect on sperm traits, revealing a $90 \%$ reduction in total living sperm quantity. Such non-linear dose-responses, wherein low dosages can induce more profound effects than higher dosages, are well documented (Tosi and Nieh, 2019; Tosi et al., 2016), yet the underlying reasons remain to be fully understood (Vandenberg et al., 2012; Lagarde et al., 2015). Despite only a small fraction of transferred sperm being stored in the female spermatheca $\left(\sim 4^{\prime} 000\right)$ (Fliszkiewicz et al., 2013), any decrease in living sperm quantity could have negative consequences for the production of female offspring. Indeed, Osmia bicornis and O. lignaria exposed to neonicotinoids at field-realistic concentrations yielded not only significantly fewer offspring but also a significantly stronger male-biased sex ratio (Sandrock et al., 2014; Stuligross and Williams, 2020). Impaired female provisioning efficiency leading to investment in 
the less costly male offspring may contribute (Stuligross and Williams, 2020; Seidelmann, 2014b). Alternatively, but not mutually exclusive, non-viable sperm can result in non-intentional male offspring in Hymenoptera (i.e., ovipositing females release sperm to produce a daughter (Beye et al., 2003), but the sperm fails to fertilize the egg resulting in a son). Irrespective of the reproductive rate (which is low in solitary bees (Raw, 1972)), any decrease in female offspring production will almost certainly lead to a reduced reproductive potential of subsequent generations; ultimately having detrimental effects on entire populations. This will have even more severe consequences in insect species where unfertilized eggs will simply not hatch (Sander, 2012).

Due to their systemic nature and common applications, populations globally are very likely to encounter neonicotinoid pollution at similar concentrations as tested in our study (Zioga et al., 2020; Calvo-Agudo et al., 2019; Martínez-Ferrer et al., 2019; Mitchell et al., 2017). Given that neonicotinoid exposure will similarly affect male fertility across taxa, which seems very likely due to the non-specific mode of action (Matsuda et al., 2020), we have reasons to believe that we are experiencing a déjà-vu. Indeed, there is consensus that certain agrochemicals, i.e., DDT, had a major impact on reproductive health even in remote areas (Ratcliffe, 1967; Anthony et al., 1999; Heath et al., 1969) and were banned accordingly (Grier, 1982). Nevertheless, even today we are suffering the aftermath of DDT pollution (Silva et al., 2019; (Sánchez-Bayo and Wyckhuys, 2019a)). Taken together, the inevitable interaction of environmental pollutants with climate change (Soroye et al., 2020), habitat loss (Dirzo et al., 2014), and other anthropogenic stressors reflects a Sisyphean challenge to prevent the global meltdown scenario for biodiversity. Since human population growth and per capita consumption cannot be addressed within functional ethical frameworks, reducing environmental pollution such as the indiscriminate use of agrochemicals, e.g., via sustainable food production (Wyckhuys et al., 2021), is the only way forward to decelerate the ongoing loss of biodiversity.

\section{Declaration of competing interest}

The authors declare that they have no known competing financial interests or personal relationships that could have appeared to influence the work reported in this paper.

\section{Acknowledgments}

We sincerely thank Angela Minnameyer and Domenic Camenzind for their undisputed efforts in performing routine laboratory work that contributed to data collection. Without their assistance this project would not have been possible. Maria a Marca and Christoph Moor from the Swiss Federal Office of the Environment (FOEN) and Lukas Jeker from the Swiss Bee Research Centre, Agroscope, engaged us in fruitful discussions.

\section{Author contributions}

V.S.: Developed the concept underlying the experiment, contributed to designing the experiment, executed the experiment, analyzed and interpreted the data, and wrote the first draft of the manuscript. M.A.: Co-conceptualized the experiment and significantly contributed to the interpretation of data and writing the manuscript; he also contributed to the statistical analyses and their interpretation. L.V.-B.: Co-conceptualized the experiment, and significantly contributed to designing and performing the statistical analyses, and writing the manuscript. S.T.: Co-conceptualized the experiment and significantly contributed to designing and performing the statistical analyses, and writing the manuscript. P.N.: Conceptualized the experiment together with V.S. and L.S., and significantly contributed to designing the experiment, interpreting the data, and writing the first draft of the manuscript. He also provided laboratory material, reagents, and laboratory facilities. L.S.: Developed the concept underlying the experiment, contributed to designing the experiment, executed the experiment, provided laboratory material and reagents, and, together with V.S. analyzed and interpreted the data, and wrote the first draft of the manuscript.

\section{Funding}

Support was provided by the Swiss Ferderal Office of the Environment (FOEN) to L.S. and P.N. (16.0091.PJ/R102-1664), by Agroscope to V.S., L.S., M.A., and P.N., and by the Vinetum Foundation to V.S. and P.N.

\section{Data accessibility}

The complete raw data can be found at the Dryad repository. See: https://doi.org/10.5061/dryad.djh9w0vzq.

\section{Appendix A. Supplementary data}

Supplementary data to this article can be found online at https://doi.org/10.1016/j.envpol.2021.117106.

\section{References}

Agarwal, A., et al., 2020. Male infertility. Lancet 6736, 1-15.

Anthony, R.G., Miles, A.K., Estes, J.A., Isaacs, F.B., 1999. Productivity, diets, and environmental contaminants in nesting bald eagles from the Aleutian archipelago. Environ. Toxicol. Chem. 18, 2054-2062.

Arena, M., Sgolastra, F., 2014. A meta-analysis comparing the sensitivity of bees to pesticides. Ecotoxicology 23, 324-334.

Azpiazu, C., et al., 2019. Chronic oral exposure to field- realistic pesticide combinations via pollen and nectar: effects on feeding and thermal performance in a solitary bee. Sci. Rep., 9:13770

Baer, B., Heazlewood, J.L., Taylor, N.L., Eubel, H., Millar, A.H., 2009. The seminal fluid proteome of the honeybee Apis mellifera. Proteomics 9, 2085-2097.

Bal, R., et al., 2012. Effects of clothianidin exposure on sperm quality, testicular apoptosis and fatty acid composition in developing male rats. Cell Biol. Toxicol. 187-200. https://doi.org/10.1007/s10565-012-9215-0.

Baron, G.L., Raine, N.E., Brown, M.J.F., 2017. General and species-specific impacts of a neonicotinoid insecticide on the ovary development and feeding of wild bumblebee queens. Proc. R. Soc. B Biol. Sci. 284.

Beadle, K., et al., 2019. Genomic insights into neonicotinoid sensitivity in the solitary bee Osmia bicornis. PLoS Genet. 15, e1007903.

Bélanger, J., Pilling, D., 2019. The State of the World's Biodiversity for Food and Agriculture. Food and Agriculture Organization of the United Nations (FAO), 20193206813.

Beye, M., Hasselmann, M., Fondrk, M.K., Page, R.E., Omholt, S.W., 2003. The gene csd is the primary signal for sexual development in the honeybee and encodes an SR-type protein. Cell 114, 419-429.

Birkhead, T.R., Hosken, D.J., Pitnick, S.S., 2009. Sperm Biology. Elsevier. https:// doi.org/10.1016/B978-0-12-372568-4.X0001-8.

Bosch, J., 1992. Parasitism in wild and managed populations of the almond pollinator Osmia cornuta Latr. (Hymenoptera, Megachilidae). J. Apicult. Res. 31, 77-82.

Brandt, A., et al., 2020. Immunosuppression response to the neonicotinoid insecticide thiacloprid in females and males of the red mason bee Osmia bicornis $\mathrm{L}$. Sci. Rep. 10, 1-10.

Breeze, T.D., et al., 2020. Pollinator monitoring more than pays for itself. J. Appl. Ecol. 1365-2664, 13755. https://doi.org/10.1111/1365-2664.13755.

Bresslau, E. Der, 1905. Samenblasengang der Bienenkönigin. Zool. Anz. 29, 299-325.

Bretveld, R., Brouwers, M., Ebisch, I., Roeleveld, N., 2007. Influence of pesticides on male fertility. Scand. J. Work. Environ. Health 33, 13-28.

Browne, F.B., 1922. On the life-history of Melittobia acasta, Walker; a chalcid parasite of bees and wasps. Parasitology 14, 349-370.

Calvo-Agudo, M., et al., 2019. Neonicotinoids in excretion product of phloemfeeding insects kill beneficial insects. Proc. Natl. Acad. Sci. U.S.A. 116, $16817-16822$.

Cane, J.H., 2016. Adult pollen diet essential for egg maturation by a solitary Osmia bee. J. Insect Physiol. https://doi.org/10.1016/j.jinsphys.2016.09.011. 
Cardinale, B.J., et al., 2012. Biodiversity loss and its impact on humanity. Nature 486 (7401), 59-67.

Carvalho, F.P., 2006. Agriculture, pesticides, food security and food safety. Environ. Sci. Pol. 9, 685-692.

Castellini, C., et al., 2020. Bisphenol A and male fertility: myths and realities. Front. Endocrinol. 11, 1-10.

Ceballos, G., Ehrlich, P.R., Dirzo, R., 2017. Biological annihilation via the ongoing sixth mass extinction signaled by vertebrate population losses and declines. Proc. Natl. Acad. Sci. U.S.A. 114, E6089-E6096.

Ceballos, G., Ehrlich, P.R., Raven, P.H., 2020. Vertebrates on the brink as indicators of biological annihilation and the sixth mass extinction. Proc. Natl. Acad. Sci. Unit. States Am. 117, 201922686.

Ciereszko, A., et al., 2017. Sperm parameters of honeybee drones exposed to imidacloprid. Apidologie 48, 211-222.

Cleves, A.M., 2002. How do I analyze multiple failure-time data using Stata? Stata FAQ. Available from: URL. http://www.stata.com/support/faqs/stat/stmfail.html.

Cleves, A.M., Gould, W.W., Marchenko, Y.V., 2016. An Introduction to Survival Analysis Using Stata. Stata Press.

Collins, A.M., Williams, V., Evans, J.D., 2004. Sperm storage and antioxidative enzyme expression in the honey bee, Apis mellifera. Insect Mol. Biol. 13, $141-146$.

Desneux, N., Decourtye, A., Delpuech, J.M., 2007. The sublethal effects of pesticides on beneficial arthropods. Annu. Rev. Entomol. 52, 81-106.

Díaz, S., et al., 2019. Pervasive human-driven decline of life on Earth points to the need for transformative change. Science 366 (1327), eaax3100.

Dirzo, R., et al., 2014. Defaunation in the anthropocene. Science 345 (6195), 401-406.

Douglas, M.R., Rohr, J.R., Tooker, J.F., 2015. Neonicotinoid insecticide travels through a soil food chain, disrupting biological control of non-target pests and decreasing soya bean yield. J. Appl. Ecol. 52, 250-260.

Duchateau, M.J., Mariën, J., 1995. Sexual biology of haploid and diploid males in the bumble bee Bombus terrestris. Insectes Soc. 42, 255-266.

Fliszkiewicz, M., Langowska, A., Tryjanowski, P., 2013. Insemination in female biased groups of Osmia bicornis. J. Apicult. Sci. 57, 73-79.

Friedli, A., Williams, G.R., Bruckner, S., Neumann, P., Straub, L., 2020. The weakest link: haploid honey bees are more susceptible to neonicotinoid insecticides. Chemosphere 242, 125145.

Grier, J.W., 1982. Ban of DDT and subsequent recovery of reproduction in bald eagles. Science 218 (4578), 1232-1234.

Heath, R.G., Spann, J.W., Kreitzer, J.F., 1969. Marked DDE impairment of mallard reproduction in controlled studies. Nature 224, 47-48.

Henry, M., et al., 2015. Reconciling laboratory and field assessments of neonicotinoid toxicity to honeybees. Proc. R. Soc. B 282.

Horejs, C., 2020. Solutions to plastic pollution. Nat. Rev. Mater. 5, 641.

Humann-Guilleminot, S., et al., 2019. A sublethal dose of the neonicotinoid insecticide acetamiprid reduces sperm density in a songbird. Environ. Res. 177, 108589.

Hunter, F.M., Birkhead, T.R., 2002. Sperm viability and competiton in insects. Curr. Biol. 12, 121-123.

Koeniger, G., 1986. Reproduction and mating behavior. in Bee Genetics and Breeding, pp. 255-280. https://doi.org/10.1016/b978-0-12-588920-9.50015-7.

Lagarde, F., et al., 2015. Non-monotonic dose-response relationships and endocrine disruptors: a qualitative method of assessment -No section-. Environ. Heal. A Glob. Access Sci. Source 14, 1-15.

Leckie, G., 2010. Centre for Multilevel Modeling, LEMMA VLE. Centre for Multilevel Modeling.

Lumley, A.J., et al., 2015. Sexual selection protects against extinction. Nature 522, 470-473.

Martínez-Ferrer, M.T., Campos-Rivela, J.M., Hernando-Guil, M.D., GarcíaValcárcel, A.I., 2019. Evaluation of residue levels of imidacloprid and thiamethoxam after foliar application to the citrus varieties Lane Late, Valencia Late, Rohde Summer, and Nules. J. Econ. Entomol. 112, 2676-2685.

Matsuda, K., Ihara, M., Sattelle, D.B., 2020. Neonicotinoid insecticides: molecular targets, resistance, and toxicity. Annu. Rev. Pharmacol. Toxicol. 60, 241-255.

Mitchell, M.N., 2012. Interpreting and Visualizing Regression Models Using Stata. Stata Press.

Mitchell, E.A.D., et al., 2017. A worldwide survey of neonicotinoids in honey. Science 358 (6359), 109-111.

Mobley, M.W., Gegear, R.J., 2018. One size does not fit all: caste and sex differences in the response of bumblebees (Bombus impatiens) to chronic oral neonicotinoid exposure. PloS One 13, 1-16.

Muth, F., Gaxiola, R.L., Leonard, A.S., 2020. No evidence for neonicotinoid preferences in the bumblebee Bombus impatiens. R. Soc. Open Sci. 7.

NCSS, 2020. 2020 Statistical Software. NCSS, LLC, Kaysville, Utah, USA. https://ncss. com/software/ncss.

Njiwa, J.R.K., Müller, P., Klein, R., 2004. Binary mixture of DDT and Arochlor1254: effects on sperm release by Danio rerio. Ecotoxicol. Environ. Saf. 58, 211-219.

Ratcliffe, D.A., 1967. Decrease in eggshell weight in certain birds of prey. Nature 215, $208-210$.

Ravitsky, V., Kimmins, S., 2019. The forgotten men: rising rates of male infertility urgently require new approaches for its prevention, diagnosis and treatment. Biol. Reprod. 101, 872-874.

Raw, A., 1972. The biology of the solitary bee Osmia rufa (L.) (Megachilidae). Trans. R. Entomol. Soc. Lond. 124, 213-229.

Rhouma, K.B., Tebourbi, O., Krichah, R., Sakly, M., 2001. Reproductive toxicity of DDT in adult male rats. Hum. Exp. Toxicol. 20, 393-397.

Rundlöf, M., et al., 2015. Seed coating with a neonicotinoid insecticide negatively affects wild bees. Nature 521, 77-80.

Sala, O.E., et al., 2000. Global biodiversity scenarios for the year 2100. Science 287 (5459), 1770-1774.

Sales, K., et al., 2018. Experimental heatwaves compromise sperm function and cause transgenerational damage in a model insect. Nat. Commun. 9, 1-11.

Sánchez-Bayo, F., 2014. The trouble with neonicotinoids. Science 346 (6211), 806-807.

Sánchez-Bayo, F., Wyckhuys, K.A.G., 2019. Worldwide decline of the entomofauna: a review of its drivers. Biol. Conserv. 232, 8-27.

Sander, K., 2012. Fertilization and egg cell activation in insects. Biology of fertilization 2, 409-430.

Sandrock, C., et al., 2014. Sublethal neonicotinoid insecticide exposure reduces solitary bee reproductive success. Agric. For. Entomol. 16, 119-128.

Schläppi, D., Kettler, N., Straub, L., Glauser, G., Neumann, P., 2020. Long-term effects of neonicotinoid insecticides on ants. Commun. Biol. 3, 1-9.

Schwenke, R.A., Lazzaro, B.P., Wolfner, M.F., 2016. Reproduction-immunity tradeoffs in insects. Annu. Rev. Entomol. 61, 239-256.

Seidelmann, K., 2006. Open-cell parasitism shapes maternal investment patterns in the Red Mason bee Osmia rufa. Behav. Ecol. 839-848. https://doi.org/10.1093/ beheco/arl017.

Seidelmann, K., 2014. Behavioural induction of unreceptivity to mating from a postcopulatory display in the red mason bee, Osmia bicornis. Behaviour 151, $1687-1702$.

Seidelmann, K., 2014. Optimal progeny body size in a solitary bee, Osmia bicornis (Apoidea: megachilidae). Ecol. Entomol. 39, 656-663.

Seidelmann, K., 2015. Double insurance of paternity by a novel type of mating plug in a monandrous solitary mason bee Osmia bicornis (Hymenoptera: Megachilidae). Biol. J. Linn. Soc. 115, 28-37.

Silva, V., et al., 2019. Pesticide residues in European agricultural soils - a hidden reality unfolded. Sci. Total Environ. 653, 1532-1545.

Smith, R.L., 1984. Sperm Competition and the Evolution of Animal Mating Systems. Elsevier.

Snodgrass, R.E., 1962. The Anatomy of the Honey Bee. Hardpress Publishing.

Soroye, P., Newbold, T., Kerr, J., 2020. Climate change contributes to widespread declines among bumble bees across continents. Science 367 (6478), 685-688.

Sribney, W., StataCorp, 2005. Why should I not do a likelihood-ratio test after an ML estimation (e.g., logit, probit) with clustering or pweights? Copyright 1996-2016 StataCorp LP.

Straub, L., Williams, G.R.G.R., Pettis, J., Fries, I., Neumann, P., 2015. Superorganism resilience: eusociality and susceptibility of ecosystem service providing insects to stressors. Curr. Opin. Insect Sci. 12, 109-112.

StataCorp, 2019. StataCorp. 2019. Stata Statistical Software: Release 16. StataCorp LLC, College Station, TX.

Straub, L., et al., 2016. Neonicotinoid insecticides can serve as inadvertent insect contraceptives. R. Soc. Proc. B 283, 20160506.

Strobl, V., et al., 2019. Not every sperm counts: male fertility in solitary bees, Osmia cornuta. PLoS One 14, e0214597.

Strobl, V., et al., 2020. Positive correlation between pesticide consumption and longevity in solitary bees: are we overlooking fitness trade-offs? Insects 11 , $1-12$.

Stuligross, C., Williams, N.M., 2020. Pesticide and resource stressors additively impair wild bee reproduction. Proc. R. Soc. B 287.

Thompson, H.M., Pamminger, T., 2019. Are honeybees suitable surrogates for use in pesticide risk assessment for non-Apis bees? Pest Manag. Sci. 75, 2549-2557.

Thornhill, R., Alcock, J., 1983. The Evolution of Insect Mating Systems. Harvard University Press. Harvard University Press, Cambridge, MA.

Torchio, P.F., Asensio, E., W., T. R., 1987. Introduction of the European bee, Osmia cornuta, into California almond orchards (Hymenoptera: megachilidae). Environ. Entomol. 16, 664-667.

Tosi, S., Nieh, J.C., 2017. A common neonicotinoid pesticide, thiamethoxam, alters honey bee activity, motor functions, and movement to light. Sci. Rep. 7, 1-13.

Tosi, S., Nieh, J.C., 2019. Lethal and sublethal synergistic effects of a new systemic pesticide, flupyradifurone (Sivantow), on honeybees. Proc. R. Soc. B Biol. Sci. 286, 1-9.

Tosi, S., et al., 2016. Effects of a neonicotinoid pesticide on thermoregulation of African honey bees (Apis mellifera scutellata). J. Insect Physiol. 93-94, 56-63.

Tosi, S., Burgio, G., Nieh, J.C., 2017. A common neonicotinoid pesticide, thiamethoxam, impairs honey bee flight ability. Sci. Rep. 7, 1201.

Turturro, A., Hass, B.S., Hart, R.W., 2000. Does caloric restriction induce hormesis? Hum. Exp. Toxicol. 19, 320-329.

van Kleunen, M., et al., 2015. Global exchange and accumulation of non-native plants. Nature 525, 100-103.

Vandenberg, L.N., et al., 2012. Hormones and endocrine-disrupting chemicals: lowdose effects and nonmonotonic dose responses. Endocr. Rev. 33, 378-455.

Wagner, D.L., 2020. Insect declines in the anthropocene. Annu. Rev. Entomol. 65, $457-480$.

Wasielewski, O., Giejdasz, K., Wojciechowicz, T., Skrzypski, M., 2011. Ovary growth and protein levels in ovary and fat body during adult-wintering period in the red mason bee, Osmia rufa. Apidologie 42, 749-758.

Westrich, P., 1989. Die Wildbienen Baden-Württembergs. Eugen Ulmer Verlag, 38001-3307-5.

Whorton, D., Marshall, S., Milby, T.H., 1976. Infertility in male pesticide workers, Lancet 17, 1259-1261. 
Wiegand, R.E., 2010. Performance of using multiple stepwise algorithms for variable selection. Stat. Med. 29, 1647-1659.

Wood, T.J., et al., 2020. Managed honey bees as a radar for wild bee decline? Apidologie. https://doi.org/10.1007/s13592-020-00788-9.

Woodcock, B.A., et al., 2016. Impacts of neonicotinoid use on long-term population changes in wild bees in England. Nat. Commun. 7, 12459.

Woyke, J., Ruttner, F., 1958. An anatomical study of the mating process in the honeybee. Bee World 39, 1-18.
Wyckhuys, K., et al., 2021. Stay true to integrated pest management. Science 371 (6525), 133.

Xie, W., et al., 2012. Gene expression profiling in the thiamethoxam resistant and susceptible B-biotype sweetpotato whitefly, Bemisia tabaci. J. Insect Sci. 12 , $1-14$.

Zioga, E., Kelly, R., White, B., Stout, J.C., 2020. Plant protection product residues in plant pollen and nectar: a review of current knowledge. Environ. Res. 189. 